\title{
Reflexiones sobre el presente y el futuro de la ciencia, la tecnología, la educación y el país
}

\author{
Enrique Forero \\ Presidente, \\ Academia Colombiana de Ciencias Exactas, Físicas y Naturales \\ Presidente \\ Colegio Máximo de las Academias de Colombia
}

\section{Introducción}

¿Puede la comunidad científica y académica de Colombia proponer cambios sustanciales en la forma como el país mira a la ciencia, la tecnología y educación?

¿Están nuestras universidades capacitadas para liderar el proceso de cambio que necesita el país?

Las respuestas a estas preguntas no están al alcance de la mano. La crisis por la que atraviesa la educación a todos los niveles es de extrema gravedad. Es una crisis con características casi que universales. Y la ciencia y la tecnología enfrentan situaciones de crisis semejantes, por las más diversas razones. Trataré en las próximas líneas de expresar algunas opiniones al respecto, basadas en mi percepción de lo que está ocurriendo en Colombia en estas áreas.

\section{La educación básica y media}

Es interesante anotar que la crisis en la educación no es solo de Colombia o de América Latina. Escuché recientemente una conferencia del Presidente de la Academia de Ciencias de la India, el Dr. Raghavendra Gadagkar, quien fue muy claro al decir que la crisis en la educación es mundial. Y agregó que la única forma de enfrentar los retos del siglo XXI es alimentando $\mathrm{y}$ cuidando la mente humana, principalmente las mentes de las nuevas generaciones, porque ellas son las herramientas que nos permitirán inventar y construir un nuevo mundo. Debemos alimentar las mentes jóvenes y facilitarles que alcancen su potencial total, sin moldearlos a nuestras especificaciones.
Gadagkar cita el libro de Alison Gopnik del año 2016, "El carpintero y el jardinero", que estaba dirigido a los padres de familia pero que es excelente consejo también para los maestros. De acuerdo con Gopnik, no debemos ser carpinteros $\mathrm{y}$ "moldear a los niños en un producto final que encaja en el esquema que teníamos preparado desde el comienzo". Por el contrario, debemos ser jardineros y que debemos "crear un espacio protegido y apropiado para permitir que los niños florezcan".

Hoy les damos hechos en lugar de enseñarles a pensar, y destruimos su curiosidad y su creatividad y las remplazamos con "nuestro conocimiento". Tenemos aulas del siglo XIX, profesores del siglo XX y estudiantes del siglo XXI.

Recientemente el Ministerio de Educación Nacional propuso un proceso de construcción del Plan Nacional Decenal de Educación 20172026. Se crearon dos comisiones, una académica y la otra gestora. La idea era que la Comisión Académica presentara unas directrices que posteriormente la Comisión Gestora complementaría con metas, indicadores, etc. La Comisión Académica, de la que hicieron parte varios especialistas en educación junto con representantes de varias de las instituciones miembros del Colegio Máximo de las Academias de Colombia, cumplió su función y sugirió diez desafíos para los próximos 10 años.

Estos desafíos tienen que ver con el derecho a la educación, la necesidad de un sistema articulado y descentralizado, el establecimiento de lineamientos curriculares generales, flexibles 
y pertinentes, la preparación de educadores, la transformación del paradigma de transmisión de información, el uso de nuevas tecnologías, el desarrollo de la población rural, la financiación adecuada, el fomento de la investigación a todos los niveles de la educación y la búsqueda de una sociedad en paz.

No obstante, se percibe un temor al cambio. La educación del siglo XXI tiene que ser diferente. Se necesita mucha investigación en educación, que tenga en cuenta los nuevos retos que enfrenta la sociedad colombiana ante el post-conflicto, que tienen que ver con inclusión social, equidad en todos sus aspectos, respeto y ética. Aprender a crear tejido humano y a preparar a las nuevas generaciones y a los nuevos integrantes de la sociedad para una vida con mayor calidad a través del desarrollo humano integral. Preparar para la vida y no solo para el trabajo.

La ciencia, la tecnología, la innovación y la educación superior.

En semanas y meses recientes han sido motivo de preocupación para la comunidad académica y científica del país las noticias desalentadoras sobre considerables recortes presupuestales para la ciencia y la tecnología en el presupuesto nacional del año 2018 y el traslado de 1.300 billones de pesos del Fondo de Ciencia y Tecnología del Sistema General de Regalías bajo la falsa premisa de que no había buenos proyectos - para la construcción de vías terciarias o para otros fines diferentes a los originalmente definidos por la ley.

Estas noticias tienen muchas aristas que es difícil cubrir en su totalidad en este escrito. Sin embargo, vale la pena hacer algunos comentarios al respecto.

Una realidad colombiana que llama la atención es la falta de políticas de largo plazo, políticas de estado, en prácticamente todos los aspectos de la vida nacional. A esta característica tan nuestra, se agrega la total incoherencia en las actuaciones de distintos entes del gobiernos y de muchas de las decisiones gubernamentales. Así, por ejemplo, mientras se desvían 1.300 billones de pesos que eran de ciencia y tecnología, se crea el programa Colombia Científica por iniciativa del Ministerio de Educación y se solicita un préstamo del Banco Mundial por 150 millones de dólares.

Con algunas matemáticas básicas es fácil ver que con los 1.300 billones se habrían podido organizar por lo menos tres "Colombias científicas". Era necesario endeudarnos? Es Colombia Científica realmente una solución? La verdad, no lo es, es solo una financiación más para hacer algo que, por simple lógica, debería ser responsabilidad de Colciencias pues lo que se busca es fortalecer la educación superior y la investigación, obligaciones misionales de esta institución.

\section{El presente y el futuro, en manos de quién?}

El problema radica en que, sin importar los argumentos de fondo, la comunidad científica y académica, con contadas excepciones, parece refractaria a estas realidades. Muchos miembros de esas comunidades están muy cómodos en sus cargos y no parecen inmutarse ante las graves amenazas que se ciernen sobre la ciencia y la educación en el país. Son muy pocas las voces que se escuchan en respuesta a los recortes presupuestales, como si no se tratara precisamente del dinero que podría mantener sus investigaciones activas y saludables. Son poquísimas las voces que cuestionan o que al menos expresan opiniones sobre el otro programa "bandera" del gobierno, el de "ser pilo paga" y sobre la posibilidad de que ese si sea convertido en política de estado! Aunque muchas universidades están en grave estado de deterioro, son muy pocos los miembros de las respectivas comunidades que hacen conocer su preocupación ante el estado lamentable de la financiación de las universidades públicas. Parece que el problema es solamente de los directivos.

Sabemos muy bien que con el actual gobierno no se lograrán cambios profundos, ni siquiera superficiales. Pero tampoco lograremos cosa alguna con el próximo o con los siguientes si seguimos viviendo la apatía total ante las 
realidades políticas, si seguimos defendiendo agendas particulares por encima de las que tienen que ver con el presente y el futuro del país como un todo.

Es absolutamente indispensable y prioritario que la comunidad científica y académica del país tome conciencia del papel que le corresponde en la construcción del futuro de Colombia. Es fundamental que todos los colombianos reconozcamos la importancia de la única herramienta que nos da nuestra deteriorada democracia para tratar de modificar el rumbo del país en todos sus ámbitos. Esa herramienta es el voto. No es posible que sigamos siendo gobernados por personas que, además de prolongar en el tiempo las mismas castas dirigentes de toda la vida, sean elegidas con menos de la mitad de los votos posibles.

\section{Conclusión}

¿Puede la comunidad científica y académica de Colombia proponer cambios sustanciales en la forma como el país mira a la ciencia, la tecnología y educación?
¿Están nuestras universidades capacitadas para liderar el proceso de cambio que necesita el país?

Las respuestas, si bien apenas esbozadas, están en los párrafos anteriores. Esas comunidades deben asumir la responsabilidad que les corresponde en su calidad de ciudadanos, pero también de personas que con sus conocimientos $\mathrm{y}$ experiencia pueden $\mathrm{y}$ deben proponer soluciones a los graves problemas que aquejan a Colombia. No es posible que se mantengan al margen de las grandes decisiones.

El país pasará en los próximos meses por un proceso electoral difícil, en el que se alimentan sin compasión el odio y la polarización. No obstante, desde el ámbito científico y universitario puede ser posible proponer una clase diferente de debate político en el que la ciencia, la tecnología, la innovación y la educación sean elementos centrales de las campañas presidenciales y de corporaciones.

Bogotá, D.C., noviembre de 2017 


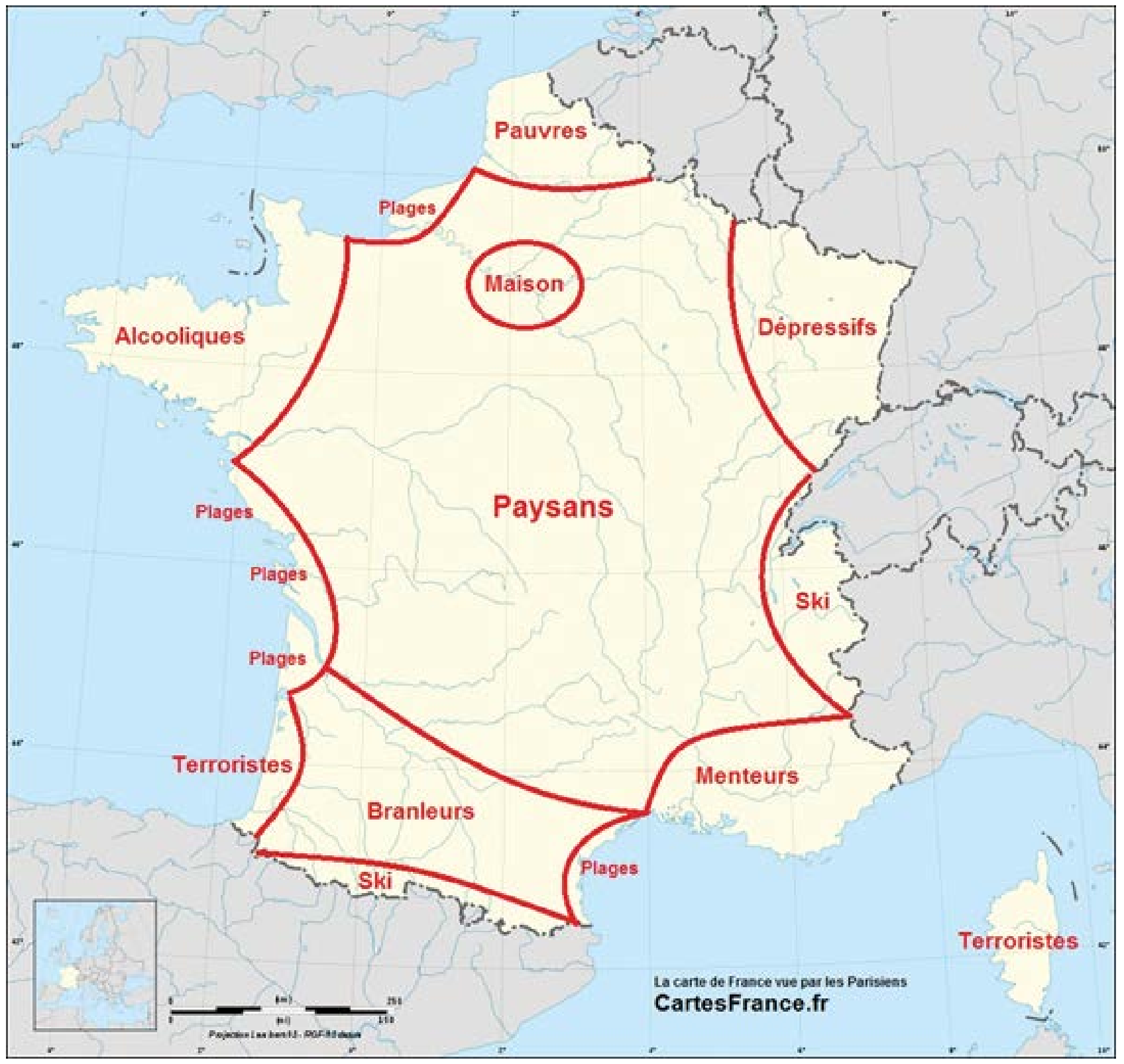

